\title{
ASSESSMENT OF RIVER BED EVOLUTION WITH THE AID OF 2D HYDRODYNAMIC MODEL WITH INTEGRATED SEDIMENT TRANSPORT MODELING CAPABILITIES
}

\author{
${ }^{1}$ Daniel BUČEK ${ }^{*}{ }^{2}$ Martin ORFÁNUS, ${ }^{3}$ Peter DUŠIČKA \\ 1,2,3 Department of Hydraulic Engineering, Faculty of Civil Engineering \\ Slovak University of Technology, Radlinského 11, 810 05, Bratislava, Slovakia \\ e-mail: ${ }^{1}$ daniel.bucek@stuba.sk, ${ }^{2}$ martin.orfanus@stuba.sk, ${ }^{3}$ peter.dusicka@stuba.sk
}

Received 31 December 2017; accepted 27 September 2018

\begin{abstract}
The aim of the study is to assess hydro-morphologic evolution of currently cut off meander for 3 river restoration scenarios during 10 days of bank-full discharge. To simulate hydro-morpho-dynamics, a numerical model with movable bed, R2DM is used. Results for scenario with partially opened meander indicate aggradation at inlet of meander and $10 \%$ decrease in flow rate. Scenario with fully opened meander shows aggradation at the inlet and 55\% decrease in flow rate. Full diversion scenario results in formation of natural river landforms (point bars, cut banks, pools, riffles) and stabilization of river bed evolution.
\end{abstract}

Keywords: Numerical hydro-dynamic modeling, River restoration, Sediment transport

\section{Introduction}

Today's appearance of the Austrian-Slovak section of river Morava is the result of the General Project of river canalization. From the end of the 30's to the mid-1960s there was an extensive systematic adjustment to lower section of river Morava. The river reach was shortened by more than $10 \mathrm{~km}$ by 16 artificial chutes. Overall, 23 meanders have been cut off [1].

Nowadays, the river channel is monotonous and the segmentation is minimal. Natural river landforms, e.g. point bars, cut banks, pools, riffles and islands are practically non-existent. Natural alternation of pools and riffles in the lower section of river Morava is also absent. Flow rate distribution is uniform in the longitudinal and

\footnotetext{
${ }^{*}$ Corresponding Author
} 
transverse flow direction. These factors contribute to gradual biotic and abiotic degradation of the river [2]. Effective and sustainable revitalization to achieve good ecological status can only be ensured by restoring original natural river processes [3].

To increase flow dynamics and improve environmental conditions in cut off meanders, a restoration project in 1996 was carried out. Four of the cut off meanders were re-connected to the main channel. The project stemmed from the Biodiversity Program - Global Environment Facility (GEF, 1994) and was funded by the World Bank. It was aimed at implementing several river restoration measures in the Morava and Rudava river basins. The aim of the project was to identify the techniques, potentials and benefits of revitalization of Morava and its ecosystems. Within this program, four cut off meanders were opened in the Slovak part of the inundation (km 12, km 19, km 65 - km 68) [1].

The subject of the work is one of these cut off meanders. In the documentation of the General Project of river canalization, is the cut off meander labeled Meander DVII and it is located on the 19th kilometer. Restoration was carried out by opening the inlet part of the meander at 1/5 of the original width and a narrow channel was excavated in the outflow section. Short after completion, a positive effect has emerged. Flow dynamics have improved, positively influencing both flora and fauna. However, the positive effect lasted for only short period of time before aggradation in the meander began to occur. During the 10 years since the revitalization, approximately 78,000 tons of sediment was deposited in the meander [1].

Currently, water interacts only at moderate to high discharge rates, but even during bank-full discharge of $250 \mathrm{~m}^{3} \cdot \mathrm{s}^{-1}$ there is near zero flow velocity in the meander. As a result, any sediment transported into the meander, is destined to aggregate there. At average to low flow rates, the meander is emptied and fish deaths occur. Long-term observation of morphological changes suggests that the method of river restoration was incorrect and contributed to even higher degree of environmental degradation [4].

The aim of the study is to assess hydro-morphological development of critical areas of the cut off meander using two-dimensional flow model for three scenarios of river restoration solutions. Focus is put on the inlet area, which, according to available studies has a key effect on the sedimentation and flow regime in the cut-off meander [1], [5]. Change in bed morphology is computed with the aid of two-dimensional hydrodynamic flow model with movable bed R2DM.

\section{Material and methods}

To conduct this study detailed topographic data of the area of interest is needed. It consists of laser altimetry topographic data, field topographic data and single-beam echo sounder data of riverbed topography. Spatial data were merged into a single digital elevation model using Geographic Information System (GIS) software. Digital elevation model was discretized with a triangular computational mesh (Fig. 1) to match characteristics of the area of interest. Resolution of the computational grid was progressively adjusted in relation to the degree of spatial segmentation of the area [6], [7]. 
The R2D software, in which the hydrodynamics of proposed variants were modeled, is a non-commercial, two-dimensional, depth averaged finite element model developed in Canada, University of Alberta [8]. Boundary conditions used in this study are bankfull discharge $Q_{\max }=250 \mathrm{~m}^{3} \cdot \mathrm{s}^{-1}$, average discharge $Q_{a v g}=114 \mathrm{~m}^{3} \cdot \mathrm{s}^{-1}$. Bank-full discharge was chosen, because for river Morava it is the flow, which transports the largest amount of sediment at the highest energy of the stream in the channel and thus has the highest impact on morpho-dynamics of the river [3]. Manning's roughness coefficient was taken from a one-dimensional hydraulic model based on the same topographic data from study MreNa [9]. Value of the used roughness coefficient was $n=0.021064$.

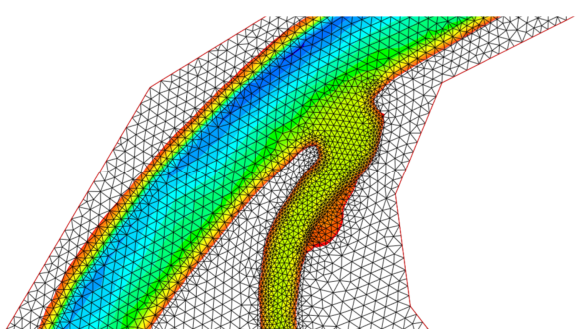

Fig. 1. Detail of computational mesh at the inlet of meander

Scenario 1 is a rather low-budget solution for increasing flow in the meander. It is designed to maintain flow through meander during average discharge and ensure minimal flow velocity of $0.3 \mathrm{~m} . \mathrm{s}^{-1}$ during bank-full discharge to ensure continuous transport of sediments [3]. The adjustment consists of widening and deepening of the original connection of the meander to the main stream. The geometry of the inlet and outlet channels was designed with a trapezoidal profile with a slope of 1: 2 with a bed altitude of $139.5 \mathrm{~m}$ a.s.l. and a bed width of $20 \mathrm{~m}$ (Fig. 2).
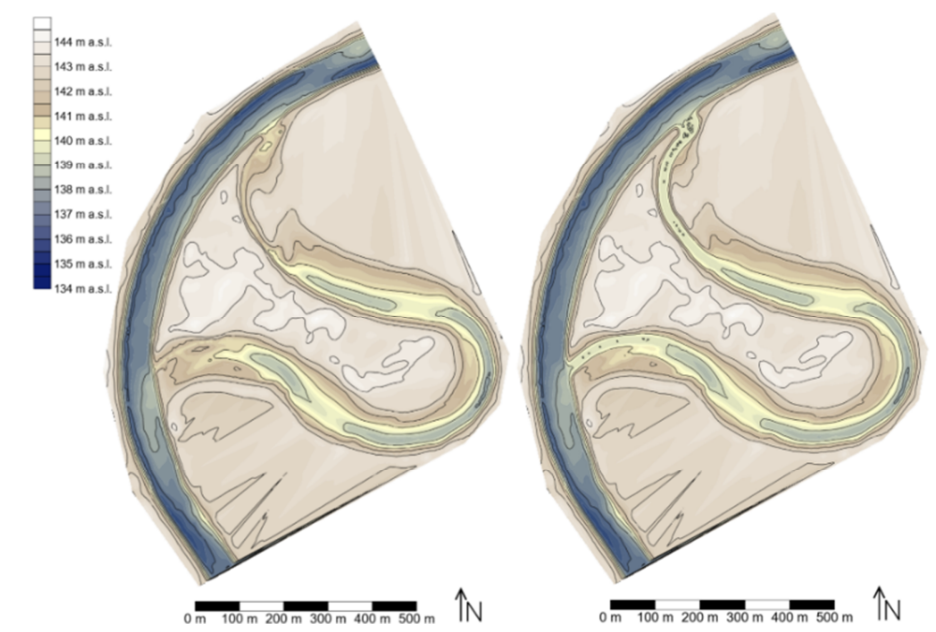

Fig. 2. Digital elevation models; left: current state, right: scenario 1 with widened inlet and outlet channels 
Scenario 2 proposes connection to the main channel with original width of the meander from before General project of river canalization. Cross section is a trapezoidal with bank slope ratio 1:3. Bed altitude is $138.0 \mathrm{~m}$. a.s.l. and the width of the bed is $60 \mathrm{~m}$ (Fig. 2). Scenario 3 is full diversion scenario connected to main channel with its original width. It is designed identically to scenario 2 with one difference, a diverting structure in the main channel to redirect total flow into the meander (Fig. 3).
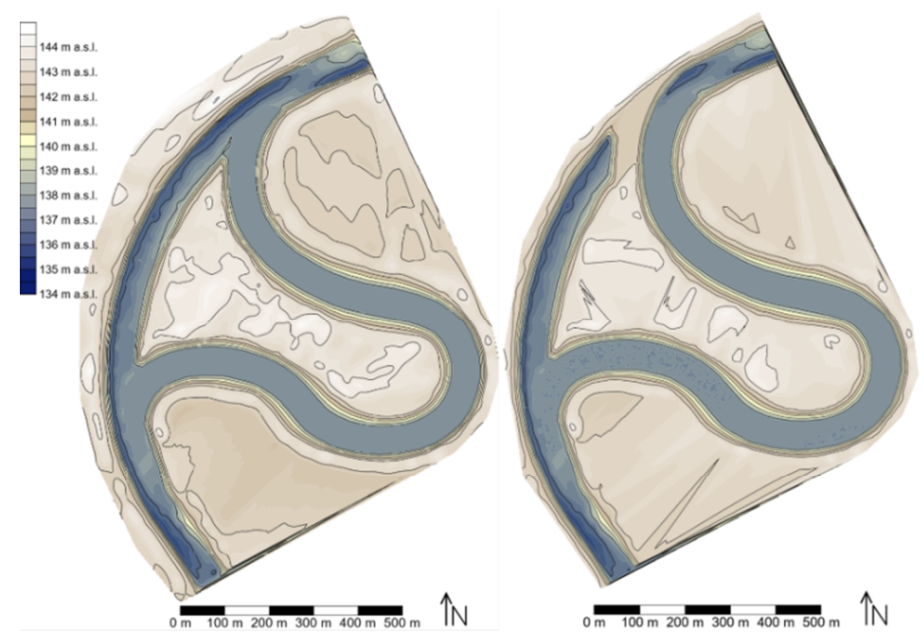

Fig. 3. Digital elevation models; left: scenario 2, right: scenario 3

River2DMorpholgy (R2DM) is a hydro-morpho-dynamic model that has been developed to simulate changes in river bed morphology. It was developed by Jose Vasquez and Robert Millar at the University of British Columbia [8]. The model solves the bed-load sediment continuity equation. Transport of fine suspended material is ignored. The hydrodynamic component of the model is based on two-dimensional, depth-averaged Saint-Venant equation. It solves the basic mass conservation equation and two components of conservation of momentum equation in the $x$ and $y$ direction. R2DM was verified in laboratory conditions on experimental channels [10].

R2DM supports five sediment transport equations: Meyer-Peter Müller, Kassem \& Chaudrey, Van Rijn, Wilcock \& Crowe and Engelund-Hansen. Each of these is suitable for different conditions [11]. Bed-load volume $q_{s}$ is the variable in the two-dimensional equation for conservation of volume (1), from which is the change in height of the riverbed for given computational node calculated,

$$
(1-\lambda) \frac{\partial z_{b}}{\partial t}+\frac{\partial q_{s x}}{\partial x}+\frac{\partial q_{s y}}{\partial y}=0
$$

where $q_{s x}, q_{s y}$ are the volumetric transport components; $\lambda$ is the porosity of riverbed material; $t$ is the time; $z_{b}$ is the height of riverbed. 
Morava is alluvial river with mainly sandy substrate and significant amount of suspended sediments. Optimal sediment transport equation for these conditions is Engelund-Hansen equation. It produced good results in large scale experiments on actual rivers [12]. Key input parameter for Engelund-Hansen equation is $D_{50}$ median grain size of the area of interest. It was set as geometric mean of all probes taken in the meander during the river restoration project in 1996 resulting in $D_{50}=0.208 \mathrm{~mm}$.

To achieve accurate values, the model needed to be calibrated. In R2DM the calibration variable is the factor for transversal slope, which directly influences the impact of the flow on transversal slope of river bed [10], [11]. The transversal slope of the flow channel is a result of the secondary (helical) flow in the curvature, which carries the particles from the concave to the convex direction. With an increasing slope, the horizontal component of the gravitational force of the particle acts against the forces of the secondary flow and the particle transport towards the convex decreases until the equilibrium occurs. In the equilibrium state, the action of the secondary flow is equal to the horizontal component of the gravitational force of the particle that acts in the downward direction. The morph-dynamic model was calibrated to the transversal slope of the main channel under the assumption, that it is formed by the helical flow of bankfull discharge, which carries the highest amount of energy to transport the bed load [3]. The goal was to achieve minimal change in transversal slope in comparison to reference profile throughout the simulated timespan of 10 days (Fig. 4). As reference profile, cross section in point of maximal curvature of the curve of the main channel was used. The transversal calibration factor 1.0 was iteratively determined as the best fit value for near zero change in transversal slope compared to the current state (Fig. 4).
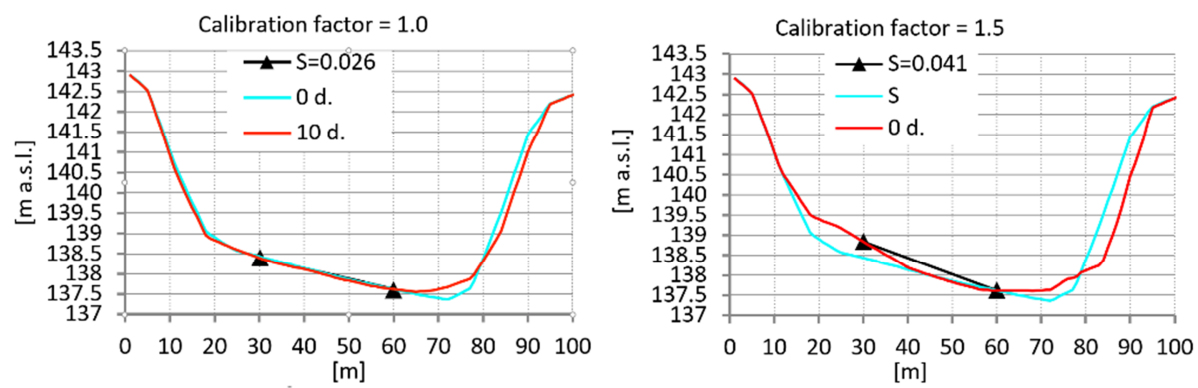

Fig. 4: Change in transversal slope after 10 simulated days of bank-full discharge; left: slope $2.6 \%$ for calibration factor 1.0 ; right: slope $4.1 \%$ for calibration factor 1.5

\section{Results and discussion}

Total simulated time of bank-full discharge $\left(250 \mathrm{~m}^{3} \cdot \mathrm{s}^{-1}\right)$ was $864000 \mathrm{~s}$ (10 days). The most significant morphological change occurred in the inlet channel of the meander.

For the scenario 1a non-linear decrease in discharge capacity of the meander was observed. Flow rate in the inlet channel of the meander dropped from the initial $15.14 \mathrm{~m}^{3} \cdot \mathrm{s}^{-1}$ to $13.7 \mathrm{~m}^{3} \cdot \mathrm{s}^{-1}$, which translates to approximately $10 \%$ of the initial flow- 
rate (Fig. 5). An amount of $2630 \mathrm{~m}^{3}$ of bedload material deposited in the inlet channel of the meander, according to the results of the numerical model (Fig. 6). Decrease in the discharge capacity caused inadequacy during average flow rate (Fig. 7). Scenario 1 is a similar solution to the Restoration project, when the meander was connected to the main stream at only $1 / 5$ of its original width, and after the first flood event it was sealed [1].

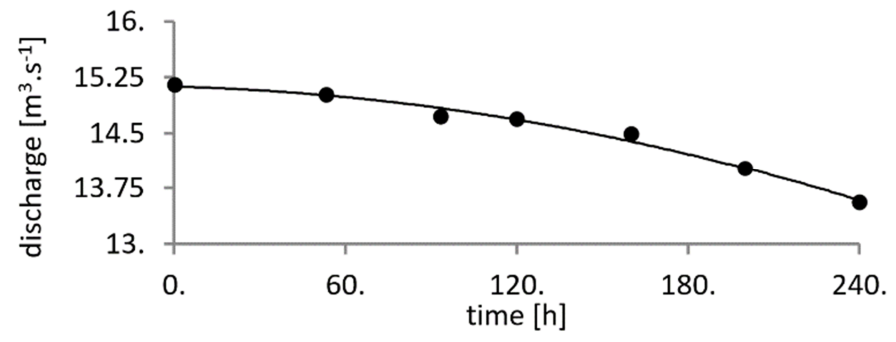

Fig. 5. Decrease in discharge capacity of the inlet channel over time due to sediment deposition

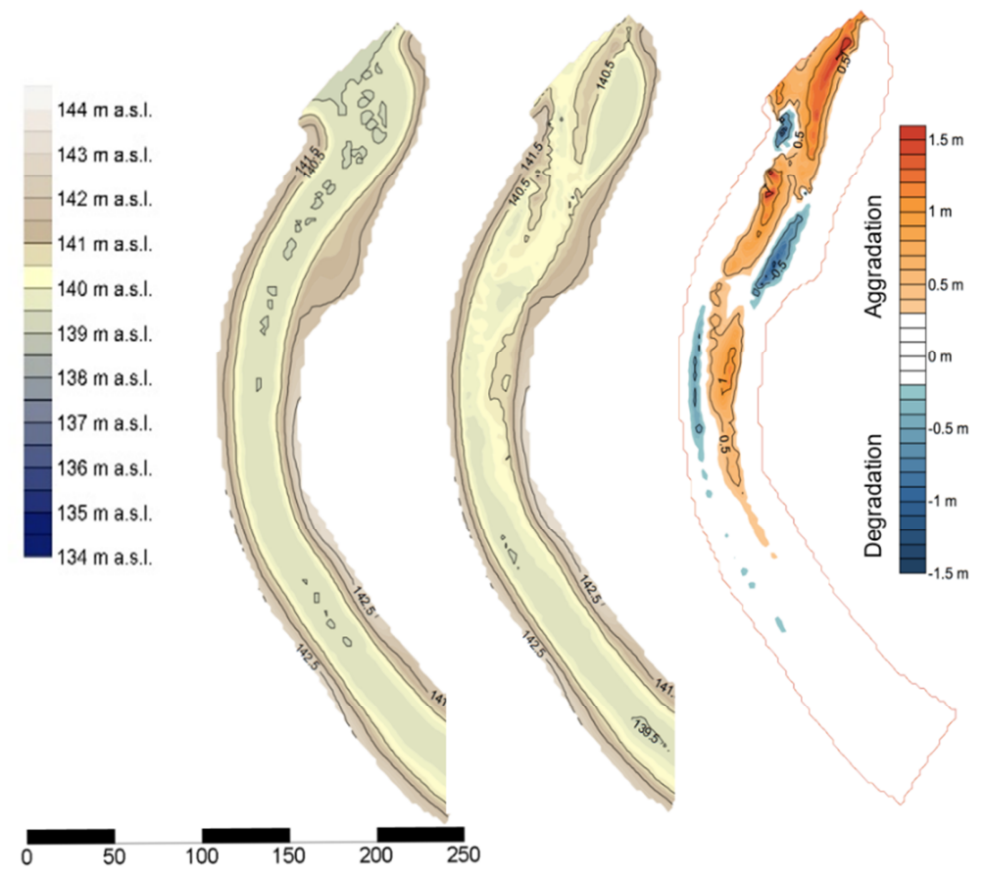

Fig. 6. Topography of inlet channel on day 0 (left); topography after 10 simulated days of bank-full discharge (middle); aggradation and degradation of material [m] (right) 


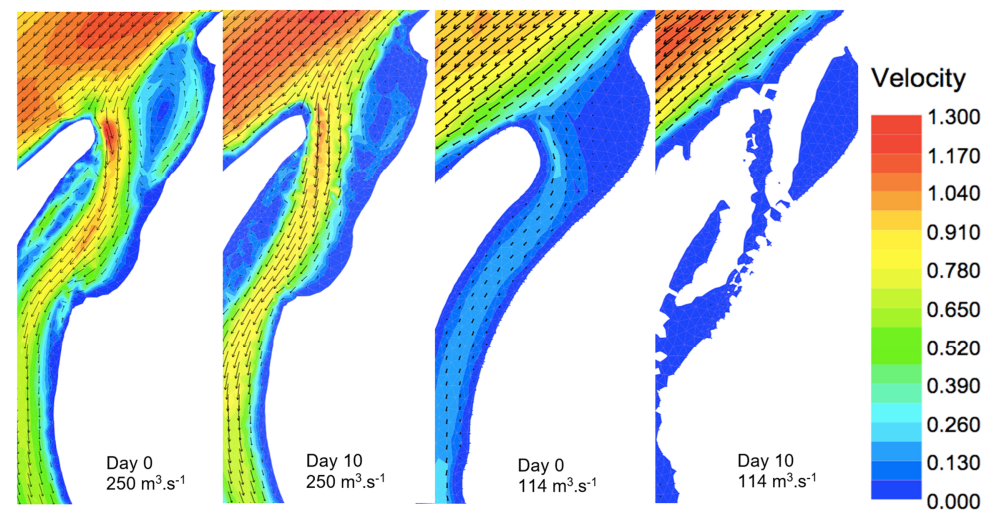

Fig. 7. Comparison of flow velocity at day 0 and day 10 for bank-full discharge of $250 \mathrm{~m}^{3} \cdot \mathrm{s}^{-1}$ and for an average flow of $114 \mathrm{~m}^{3} \cdot \mathrm{s}^{-1}$

The most significant morphological development of scenario 2 is located at the inlet of the meander. A point bar is developed on the left bank with the height of up to $2.5 \mathrm{~m}$. A scour of up to $2 \mathrm{~m}$ deep is formed on the right side of the inlet. A total of $17500 \mathrm{~m}^{3}$ ( $26.5 \mathrm{t}$ ) of material is deposited at the inlet (Fig. 8). Due to aggradation a decrease of discharge capacity occurs. From the initial $91.1 \mathrm{~m}^{3} \cdot \mathrm{s}^{-1}$ down to $40.8 \mathrm{~m}^{3} \cdot \mathrm{s}^{-1}$, this equals $55 \%$ of the initial discharge (Fig. 9).

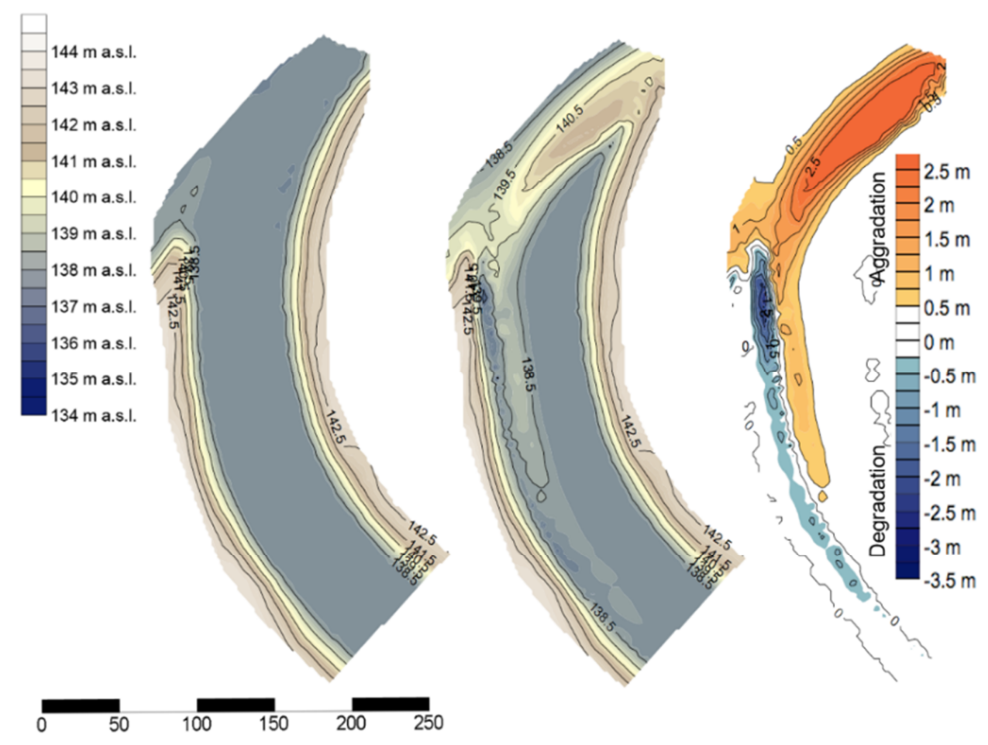

Fig. 8. Topography on inflow on day 0 (left); topography 10 days after the opening of the proposed inflow (middle); aggradation and degradation of material [m] (right) 


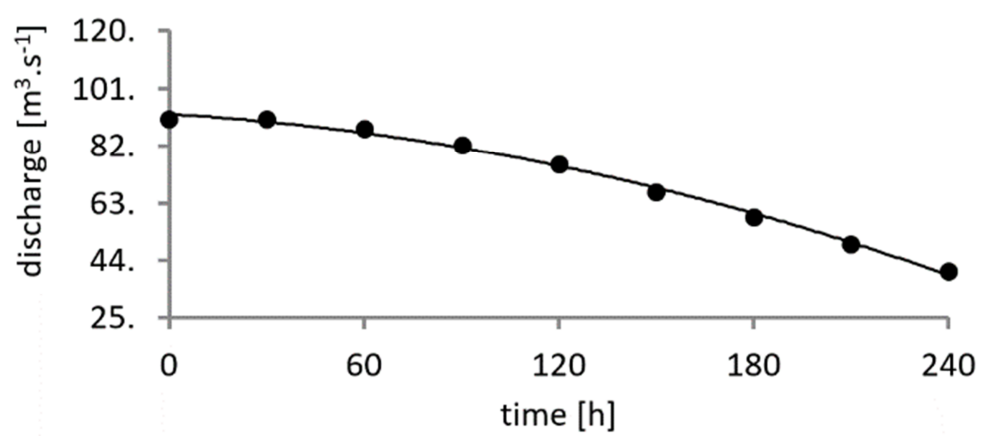

Fig. 9. Decrease in flow over time due to sediment deposition

The meander, despite the significant decrease in flow capacity, remained passable for the average flow (Fig. 10), but the tendency of intensive aggradation indicates early clogging of the inlet. Scenario 2 points to the fact, that the plain interconnection of the meander with the main channel is insufficient, even if it is connected with the original width.

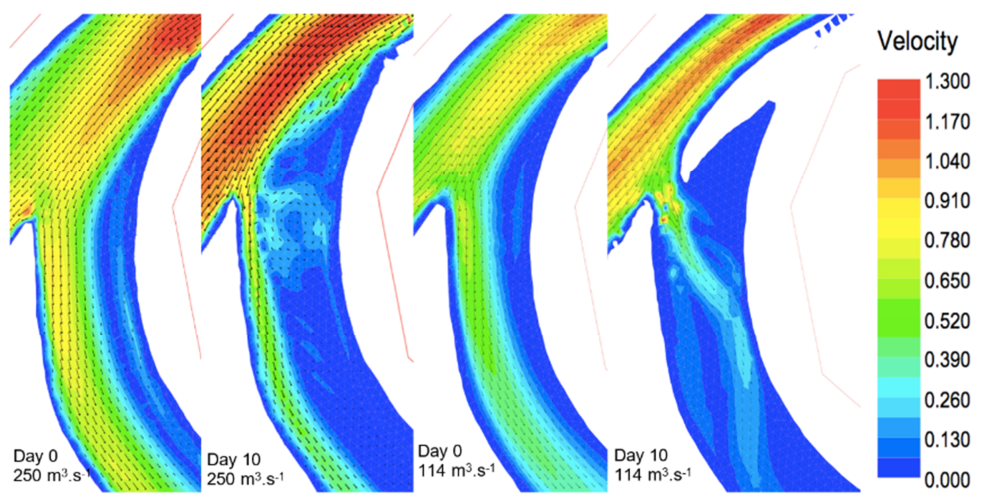

Fig. 10. Comparison of flow velocity at day 0 and day 10 for bank-full discharge of $250 \mathrm{~m}^{3} \cdot \mathrm{s}^{-1}$ and for an average flow of $114 \mathrm{~m}^{3} \cdot \mathrm{s}^{-1}$.

Scenario 3 proves to be the most sustainable and stable approach of restoration. Complete integration of the meander into the river system creates conditions for natural formation of river formations, which are a prerequisite for development diverse habitats [5]. The prognosis of development of the river bed shows the formation of alternating sections of pools and riffles, point bars, lateral bars (Fig. 11) as well as alternating areas of rapid and slow flow (Fig. 12). Inflow into the blind arm, created by the diverting structure, remains connected to the river system with minimal effect of sedimentation. This is justified by the position of the inflow, which located in the concave of the newly developed main channel. The blind arm can in the long run fulfill the role of the standing water in the area, which is insufficiently fulfilled by current cut off meander [13]. 

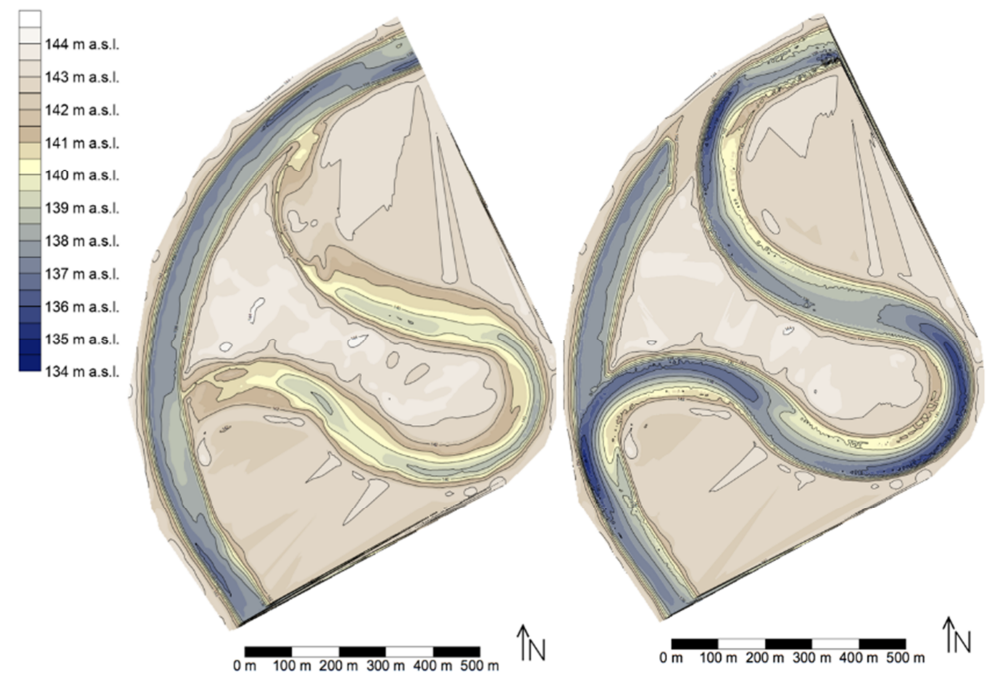

Fig. 11. Topography; current state (left); scenario 3 (right)
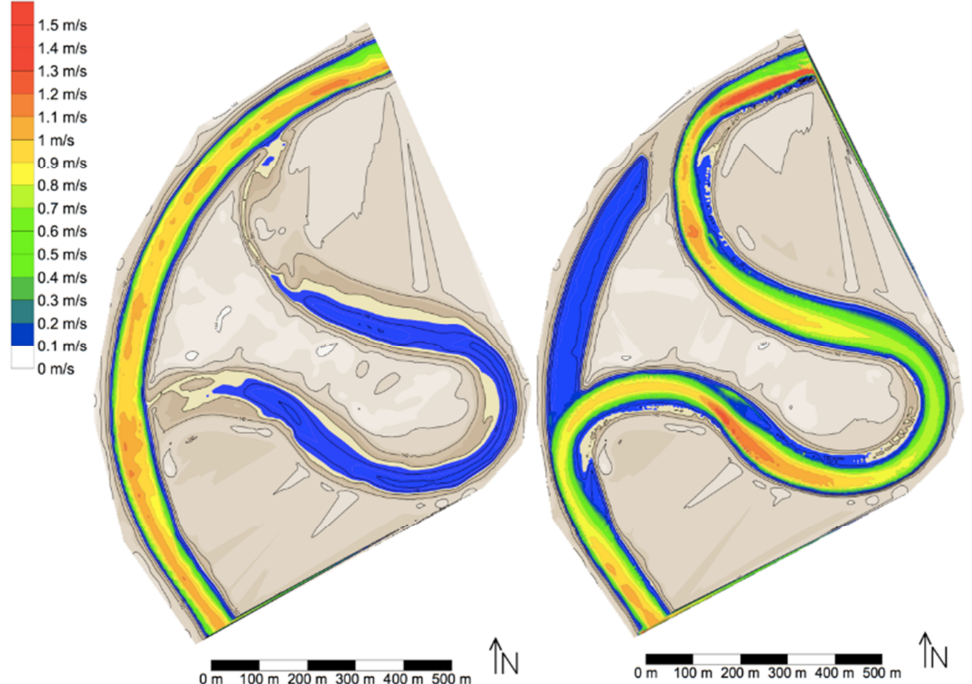

Fig. 12. Flow velocity during bank-full discharge; current state (left); scenario 3 (right)

\section{Conclusion}

Using numerical hydro-morpho-dynamic model, it was possible to evaluate, which of the proposed scenarios is the most sustainable one. Both scenarios 1 and 2 failed due to rapid aggradation in the inlet channel. Scenario 3, the full diversion scenario proves 
to be the most sustainable and stable approach of restoration. The prognosis of development of the river bed shows the formation of alternating sections of pools and riffles, point bars, lateral bars as well as alternating areas of rapid and slow flow. Implementation of this option would significantly increase the river bed's segmentation compared to the current uniform state and create conditions for the emergence of new habitats. More complex segmentation in river morphology is an important factor for improving habitat diversification and contributes to overall sustainability of local ecosystem. For the hydro-morpho-dynamic simulation, model R2DM was used. Reliability of this model was verified in laboratory conditions on experimental channels. Given the possible degree of uncertainty in approximating the real phenomenon by the equations and the method of their empirical deduction as well as in the sampling of granulometric data and hydrological data, it is advised to choose this method of analysis by comparing the efficiency of several alternative solutions.

\section{References}

[1] Holubová K. Slovak-Austrian section of morphological development of river Morava in relation to the revitalization of the river, (in Slovak), Water Research Institute, Bratislava, 2010.

[2] White S. M., Giannico G., Li H. A ‘behaviorscape' perspective on stream fish ecology and conservation: linking fish behavior to riverscapes, Wiley Interdisciplinary Reviews: Water, Vol. 1, No. 4, 2014, pp. 385-400.

[3] Holubová K., Lukáč M., Čomaj M., Mravcová K., Čuban R., Polák V., Rebenda F., Hranková R. MoRe the Morava River restoration, (in Slovak), Water Research Institute, Bratislava, 2013.

[4] Langhaus S. D., Gessner J., Hermoso V., Wolter C. Coupling systematic planning and expert judgement enhances the efficiency of river restoration, Science of the Total Environment, Vol. 560-561,2016, pp. 266-273.

[5] Palinkášová Z., Šoltész A. Hydrologic and hydraulic evaluation of drainage system in eastern Slovak Lowland, Pollack Periodica, Vol. 7, No. 3, 2012, pp. 91-98.

[6] Habersack H., Hengl M., Huber B., Lalk P., Tritthart M., River modeling - Professional aid sediment transport and river hydro-morphology, (in Austrian), Austrian Water and Wastewater Association, 2011.

[7] Iványi P. Parallel conversion of finite element meshes, Pollack Periodica, Vol. 9, No. 3, 2014, pp. 89-102.

[8] Vasquez J. Two-dimensional finite element river morphology model, PhD Thesis, The University of British Columbia, 2005.

[9] Možiešik L., Šulek P., Orfánus M., Palkovičová A., Tóthová B. Morava River Recreational navigation, (in Slovak), Waterborn Transport Development Agency, Bratislava, 2014.

[10] Kwan S. HEC River2D morphology, User Guide, University of British Columbia, 2011.

[11] Kondolf G. M., Piégay H. Tools in fluvial geomorphology, Wiley, 2003.

[12] Ghanem A., Steffler P., Hicks F., Katopodis C. Two-dimensional simulation of physical habitat conditions in flowing streams, River Research and Applications, Vol. 12, No. 2-3, 1996, pp. 185-200.

[13] Morandi B., Kail J., Toedter A., Wolter C., Piégay H. Diverse approaches to implement and monitor river restoration: A comparative perspective in France and Germany, Environmental Management, Vol. 60, No. 5, 2017, pp. 931-946. 